\title{
THE TOTAL SYNTHESIS OF THE WATER MOLD SEX HORMONE OOGONIOL
}

Toshiaki Mase, Junji Tchita, Joseph P. Marino, and Masato Koreeda*

Department of Chemistry, The University of Michigan Ann Arbor, Michigan 48109

Summary: The water mold sex hormone oogoniol (la) has been synthesized from adrenosterone in 18 steps in $7.0 \%$ overall yield. The crucial step introduces the stereochemistry at $\mathrm{C}-15$ and $\mathrm{C}-20$ through a highly efficient 1,4-addition of the organocyanocuprate generated from the side chain Grignard reagent (4) and $\mathrm{CuCN}$ to the steroidal $15 \beta, 16 \beta$-epoxy-17(20)(E)-ethylidene 2.

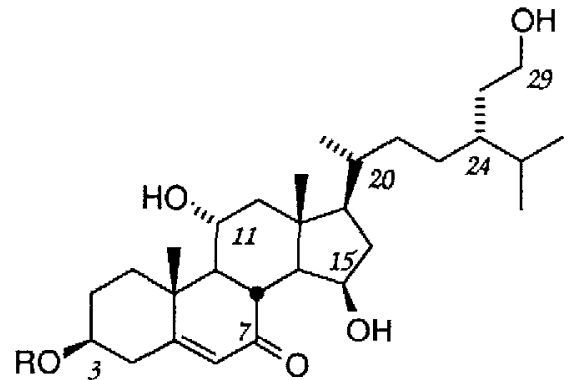

$\begin{array}{lll}\text { 1a } & \mathrm{R}=\mathrm{H} & \text { oogoniol } \\ \text { 1b } & \mathrm{R}=\mathrm{i}-\mathrm{FrCO}- & \text { oogoniol }-1 \\ \text { 1c } & \mathrm{R}=\mathrm{C}_{2} \mathrm{H}_{5} \mathrm{CO}- & \text { oogoniol }-2 \\ \text { 1d } & \mathrm{R}=\mathrm{CH}_{3} \mathrm{CO}- & \text { oogoniol }-3\end{array}$
Oogoniols (la $-\mathrm{d}),{ }^{1-3}$ steroidal sex hormones of the water mold, Achyla, possess a unique $15 \beta$-hydroxy steroid nucleus with a (24R)-29-hydroxy side chain. Introduction of a bydroxyl at $\mathrm{C}-15^{4}$ in the steroid nucleus remains a challenging synthetic problem. ${ }^{5}$ Previously, we have shown that the reaction of the $15 \beta, 16 \beta-$ epoxy-17(20)(E)-ethylidene with mixed cuprates gives the 1,4-addition product at $\mathrm{C}-20$, simultaneously establishing two chiral centers at $\mathrm{C}-15$ and $\mathrm{C}-20 .^{6}$ In this

paper, we now report that oogoniol (1a) has been synthesized from adrenosterone (ㅁ) using a modified version of this approach for the crucial, stereo- and regiocontrolled introduction of the side chain (see eq. 1).

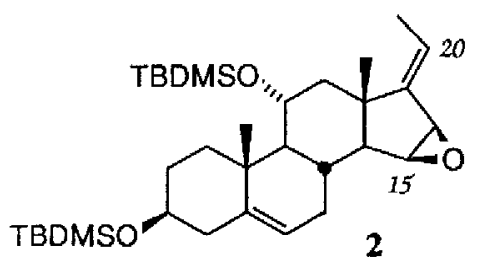

The requisite vinyl epoxide $\underline{2}$ was synthesized from adrenosterone (5) ${ }^{8}$ in 13 steps in $28.8 \%$ overall yield (Scheme I). The 3-acetoxy-3,5-diene 9 obtained from adrenosterone was selectively ketalized at $\mathrm{C}-17$ to afford 3-acetoxy-17-ethylenedioxyandrosta-3,5-dien-11-one, which was reduced with $\mathrm{NaBH}_{4}$ in $\mathrm{t}-\mathrm{BuOH} / \mathrm{THF} / \mathrm{H}_{2} \mathrm{O}^{10}$ to the $38,113-\mathrm{diol} 6$. Following the selective acetylation of the $3 \beta$-hydroxy 1 of $\underline{6}$, the stereochemistry at $C-11$ was inverted to the desired $\alpha-$ hydroxyl. Both introduction of the $\mathrm{C}-15 / 16$ doublc bond (see $\underline{8} \rightarrow \underline{9}$ ) and its epoxidation to the 


\section{Scheme $I^{\mathrm{a}}$}

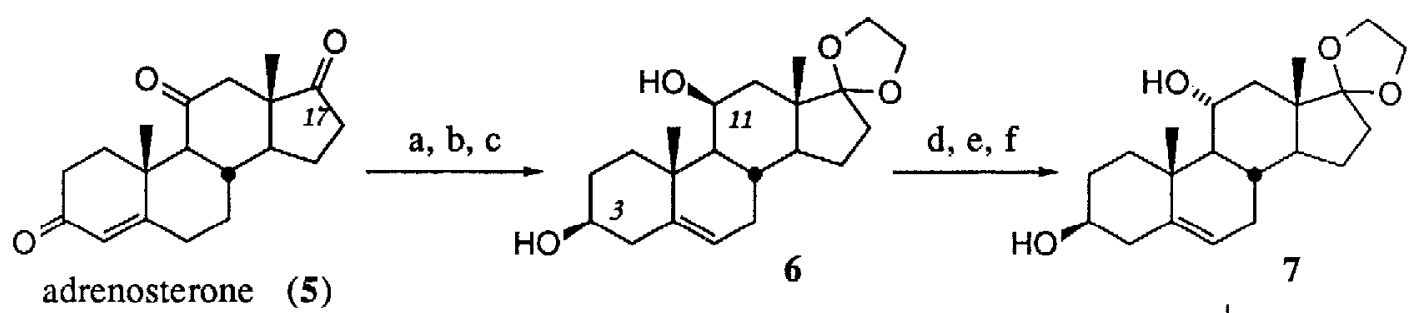
$\mathrm{g}, \mathbf{h}$

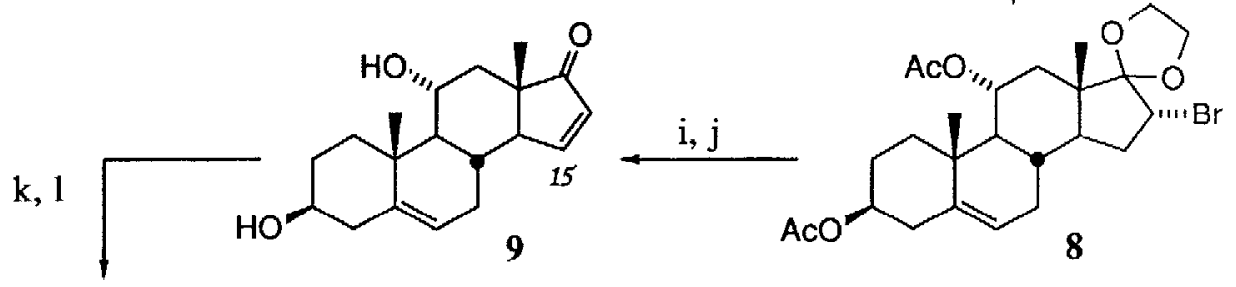

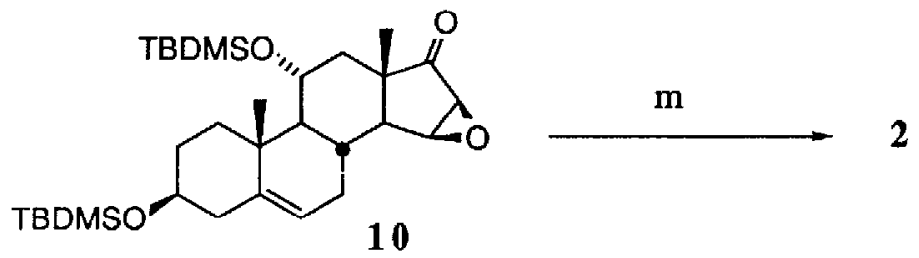

a Conditions: (a) AcCl/Ac ${ }_{2} \mathrm{O}$, reflux, 6h (92\%); (b) $\left(\mathrm{CH}_{2} \mathrm{OH}\right)_{2}, \mathrm{p}-\mathrm{TsOH}, \mathrm{HC}(\mathrm{OEt})_{3}$, reflux, th (83\%);

(c) $\mathrm{NaBH}_{4} / \mathrm{t}-\mathrm{BuOH}, \mathrm{THF}, \mathrm{H}_{2} \mathrm{O}, 0^{\circ} \mathrm{C}-\mathrm{rt}$, $5 \mathrm{~h}$ (88\%); (d) $\mathrm{Ac}_{2} \mathrm{O} / \mathrm{py}, \mathrm{rt}$ t 4h (95\%); (e) PCC, $\mathrm{CH}_{2} \mathrm{Cl}_{2}, \mathrm{r} \mathrm{t}$, 2h (99\%); () Li/liq $\mathrm{NH}_{3}$, dioxane, $\mathrm{MeOH},-30^{\circ} \mathrm{C}(99 \%)$; (g) Ac 2 O/py, rt , 8h (94\%); (h) $\mathrm{C}_{5} \mathrm{H}_{5} \mathrm{~N} \mathrm{Br}_{2}-\mathrm{HBr} /$ THF, r t , $2 \mathrm{~h}$ (work-up with $\mathrm{NaI}, \mathrm{Na}_{2} \mathrm{~S}_{2} \mathrm{O}_{3}$ ) (94\%); (i) t-BuOK (excess)/DMSO, $40^{\circ} \mathrm{C}, 24 \mathrm{~h}(86 \%$ );

(j) PPTS/acetone/ $\mathrm{H}_{2} \mathrm{O}, \mathrm{r}$ t , 24h (88\%); (k) TBDMSOTf/2,6-lutidine, $\mathrm{CH}_{2} \mathrm{Cl}_{2}, 0^{\circ} \mathrm{C}, 10 \mathrm{~min}(89 \%)$;

(l) $30 \% \mathrm{H}_{2} \mathrm{O}_{2}, 4 \mathrm{MNaOH} / \mathrm{t}-\mathrm{BuOH}, \mathrm{THF}, \mathrm{r}$, lh (85\%); (m) $\mathrm{Ph}_{3} \mathrm{P}(\mathrm{Et}) \mathrm{Br} / \mathrm{LDA} / \mathrm{THF}, 0^{\circ} \mathrm{C}, 30 \mathrm{~min}(90 \%)$

$15 \beta, 16 B$-epoxy-17-one $\left(\right.$ see $9+10$ ) were achieved, as in our previous study, ${ }^{6}$ by adopting the procedure established by Clark, I. M. et al. ${ }^{11}$ Wittig reaction of 10 with $\mathrm{Ph}_{3} \mathrm{P}(\mathrm{Et}) \mathrm{Br} / \mathrm{LDA}$ in $\mathrm{THF}^{6}$ afforded cleanly the key intermediate $17(20)(\underline{E})$-ethylidene 2 (mp $137-139^{\circ} \mathrm{C}$ ) in 90\% yield. The synthesis of the side chain bromide 15 was achieved from $(\underline{R})-(+)$-limonene (11) in 9 steps in $21.8 \%$ overall yield (Scheme II). Selective reduction of the keto-aldehyde $\underline{12}^{12}$ with $\mathrm{Li}\left(\mathrm{Et}{ }_{3} \mathrm{CO}\right) 3_{3} \mathrm{AlH}^{13}$ followed by protection of the resulting primary alcohol provided the ketone $\underline{13}$ In $73 \%$ overall yield from 11 . The use of the TBDPS group over the more commonly used TBDMS was necessary because of the observed propensity for deprotection of the latter during the ensuing Baeyer-Villiger reaction. 
Scheme II ${ }^{\mathrm{a}}$

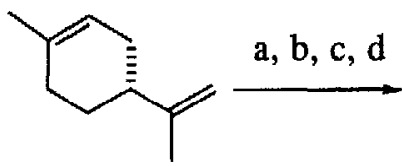

(+)-limonene (11)<smiles>CC(=O)CC[C@@H](CC=O)C(C)C</smiles>

12

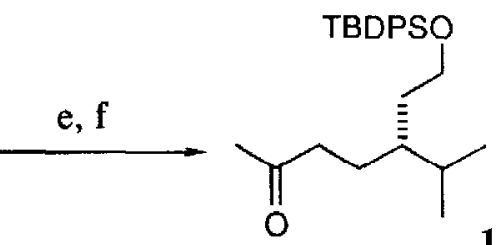

$g$

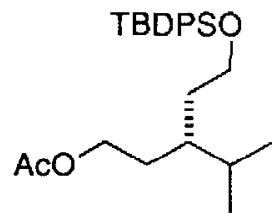

14

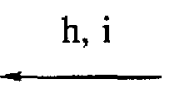

13

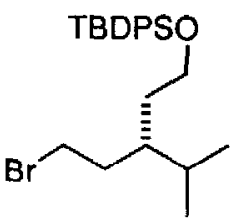

15
Conditions: (a) $5 \% \mathrm{Pt} / \mathrm{C}, \mathrm{H}_{2}, 40$ psi $\left(86 \%\right.$ ); (b) $\mathrm{HCOOH} / \mathrm{H}_{2} \mathrm{O}_{2}, 35^{\circ} \mathrm{C}$, $2 \mathrm{~h}$; (c) $\mathrm{KOH} / \mathrm{EtOH}, \mathrm{rt}, 3 \mathrm{~h}$;

(d) $\mathrm{NaIO}_{4}$ /acetone, $\mathrm{H}_{2} \mathrm{O}, \mathrm{rt}$, $4 \mathrm{~h}$ (60\% overall for b, c, and d); (e) $\mathrm{Li}\left(\mathrm{Et}_{3} \mathrm{CO}\right)_{3} \mathrm{AlH} / \mathrm{THF},-78^{\circ} \mathrm{C}$, lh ( $(78 \%$ );

(f) TBDPSCl/imidazole/DMF, $\mathrm{rt}$, 3h (94\%); (g) MCPBA/NaHCO $3, \mathrm{CH}_{2} \mathrm{Cl}_{2}$, reflux, $48 \mathrm{~h}$ (60\% yield plus $33 \%$ recovery of the starting ketone); (h) $\mathrm{K}_{2} \mathrm{CO}_{3} / \mathrm{MeOH}, 0^{\circ} \mathrm{C}$, lh (98\%); (i) $\mathrm{Ph}_{3} \mathrm{P} / \mathrm{NBS} / \mathrm{CH}_{2} \mathrm{Cl}_{2}, 0^{\circ} \mathrm{C}$, lh (98\%)

Treatment of the deep purple-colored organocyanocuprate solution in THF, prepared by adding the Grignard reagent 4 generated from bromide $\underline{15}(2.88$ equiv) to $\mathrm{CuCN}(2.85$ equiv), with the vinyl epoxide $\underline{2}$ resulted in the stereo- and regioselective formation of the desired 1 ,4-adduct 3 in $93 \%$ yield (eq. 1). 14 The stereochemistry at c-15, 20, and 24 was judged homogeneous based on the high field ${ }^{1} \mathrm{H}(360 \mathrm{MHz})$ and ${ }^{13} \mathrm{C}(90.56 \mathrm{MHz})$ NMR data. Following selective hydrogenation of the adduct $\underline{3}$ and protection of the $15 \beta$-hydroxyl as TMS ether, the 7-keto group was introduced using Salmond's reagent ${ }^{15,16}$ (Scheme III). Deprotection of the enone 16 with HF, followed by purification using silica gel chromatography, provided oogoniol (1a) as a single stereoisomer in $85 \%$ yield as a white crystalline powder (mp $101-103^{\circ} \mathrm{C}$ ). The spectroscopic properties (FTIR, $360 \mathrm{MHz}^{1} \mathrm{H}$, and $90.56 \mathrm{MHz}{ }^{13} \mathrm{C}$ NMR spectra) of the synthetic oogoniol were identical with those, kindly provided by Professor McMorris, of the natural product.

\section{Scheme III}

1. $\mathrm{H}_{2}, \mathrm{PtO}_{2} / \mathrm{AcOEt}, \mathrm{rt}, 12 \mathrm{~h}(92 \%)$

2. TMSOTf, 2,6-lutidine

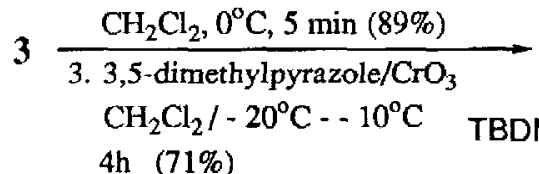
4h $(71 \%)$

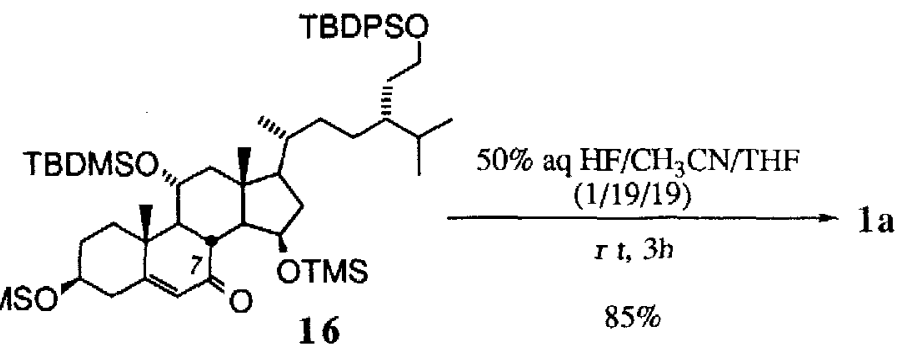


In summary, the water mold sex hormone oogoniol (la) has been synthesized from adrenosterone (5) in 18 steps in 7.0\% overall yield. The use of the Grignard-reagent derived cyanocuprate for the 1,4-addition instead of more conventional organolithium-cyanocuprate reagents is particularly noteworthy. Current efforts from these laboratories include the synthesis of oogoniols-1-3 (1b - d) . $^{17}$

Acknowledgment: We are grateful to the National Institutes of Health (DK-30025 and CA-22237 awarded to MK and JPM, respectively) for the support of this work. We thank Professor

T. C. McMorris for the spectra of oogoniol (1a).

\section{Refercnces and Footnotes}

1. McMorris, T. C.; Schow, S. R.; Weihe, G. R. Tetrahedron Lett. 19 g7 $\underline{\underline{8}}, 335$.

2. Preus, M. W.; McMorris, I. C. J. Am. Chem. Soc. 1979 $101,3066$.

3. Wiersig, J. R.; Waespe-Sarcevic, N.; Djerassi, C. J. Org. Chem. 1979, $44,3374$.

4. For rccent cxamples of other naturally occurring C-15 hydroxylated steroids, see: Minale, L.; Pizza, C.; Riccio, R.; Zollo, F. Experientia 1983, 39, 567 and Tachibana, K. ; Sakaitani, M. ; Nakanishi, K. Tetrahedron 1989, 4 , 1027 .

5. (a) Taylor, E. J.; Djerassi, C. J. Org. Chem. 1977, 42, 3571. (b) Anastasia, M.; Fiecchi, A.; Gariboldi, P.; Scala, A. Ibid. $1979,44,4 \bar{r}_{47}$ (c) McMorris, T. C.; I.e, P. H.; Preus, M. W.; Schow, S. R.; Weihe, G. R. Ibid- 1983, 48, 3370. (d) Liu, D.; Stuhi11er, L. M.; MoMorris, T. C. J. Chem. Soc. Perkin Trans. I Ig $88,2161$.

6. Marino, J. P.; Abe, H. J. Am. Chem. Soc. 19981, 103, 2907.

7. TBDMS $=$ t-butyldimethylsilyl; TRDPS $=$ t-butyldiphenylsi $7 \mathrm{yl}$.

8. Purchased from Fine Chemical Division, The Jpjohn Company, Kalamazoo, Michigan.

9. Kelly, R. W.; McClenaghan, I. ; Sykes, P. J. J. Chem. Soc. (C) 1967, 2375.

10. Edwards, J. A.; Calzada, M. C.; Ibanez, L. C.; Bowers, A. Steroids $19 \underline{\underline{6}} \underline{\underline{5}}, \underline{6}, 371$.

11. Clark, I. M.; Denny, W. A.; Jones, E. R. H.; Meakins, G. D.; Pendlebury, A.; Pinhey, J. T. I. C. S. Perkin I $19 \underline{=}=2 / 65$.

12. Kishida, Y. Chem. Ind. 1960, 465. See a1so: Nicotra, F.; Penza, L.; Ronchetti, F.; Russo, G.; Toma, L. J. Org. Chem. 1986, 51, 1272.

13. Krishnamurthy, S. I. Org. Chem. $198 \underline{=} \underline{\underline{1}}$. $46,4628$.

14. Our initial efforts for adding the side chain moiety to 2 using the cyanocuprate generated from the lithium derivative of the bromide 15 under a variety of conditions were not successful due to the difficulties encountered during the formation of the lithium derivative.

15. Salmond, W. G. ; Barta, M. A. ; Havens, J. L. J. Org. Chem. 19278, 43, 2057.

16. This oxidation did not proceed to completion even under prolonged treatment; 10 - $15 \%$ of the starting compound was recovered.

17. After completion of this work, we learned that Professor T. C. McMorris (Untversity of California, San Diego) has also achieved the total synthesis of oogoniol. (1a) using the similar dpproach described in this report. We thank Frofessor McMorris for this information.

Note Added in Proof. The synthesis of oogoniol by Professor McMorris (see footnote 17) has just appeared; Moon, S.-S.; Stuhmiller, L. M.; McMorris, T. C. J. Org. Chem. 1989, $54,26$. 